Article

\title{
Stochastic Characteristics of Manual Solar Shades and their Influence on Building Energy Performance
}

\author{
Jian Yao * and Rongyue Zheng \\ Faculty of Architectural, Civil Engineering and Environment, Ningbo University, Ningbo 315211, China; \\ rongyue@nbu.edu.cn \\ * Correspondence: yaojian@nbu.edu.cn
}

Received: 24 April 2017; Accepted: 19 June 2017; Published: 21 June 2017

\begin{abstract}
Occupant behavior has a significant impact on building energy performance. The purpose of this paper is to quantify the stochastic characteristics of manual solar shades and their influence on building energy performance. A co-simulation for occupants' stochastic control of manual solar shades was conducted and the statistic indicators (non-parameter tests and autocorrelation function) were calculated in order to identify potential occupant behavior patterns. The results show that occupants' stochastic shade control behavior among different seasons is not statistically different and that shade control behavior is not completely stochastic. Meanwhile, the trend in the fluctuation of Sc changes with time. Furthermore, a new index was introduced to evaluate the effectiveness of manual solar shades in terms of energy performance. The result shows that the effectiveness of manual solar shades is only between $39.8 \%$ and $81.3 \%$, compared with automatically controlled shades, and there is a large potential for improving the effectiveness of manual solar shades in different seasons.
\end{abstract}

Keywords: stochastic model; manual solar shades; building energy performance; co-simulation; occupant behavior

\section{Introduction}

Buildings nowadays account for approximately $40 \%$ of the total energy consumption and thus architects around the world are looking for design solutions to improve the energy performance of buildings. During the building design stage, improving the thermal performance of the building envelope (such as the external wall [1], window materials [2]) plays a significant role in building energy saving. During the building operation stage, an integrated system for buildings' energy-efficient automation can also be used to achieve a significant decrease in building energy consumption [3].

Compared to energy efficient control systems, a high performance building envelope should be first considered by architects since it ensures a low energy demand at the beginning of a building's life span. Due to the increased window to wall ratio for an improved view to outside, heat loss through windows contributes to a large fraction of building energy consumption, which has been validated by Tomás et al. using multi-objective building energy optimization [4]. Solar shading devices provide a solution for enhancing window performance. The use of solar shading devices such as overhangs [5-7], side fins [8], fixed horizontal louvers [9], etc., has been investigated by researchers. However, these studies have focused on fixed shading devices that cannot be adjusted according to outdoor conditions, and thus these solutions have a disadvantage in balancing various aspects of indoor environmental quality including energy performance, discomfort glare, the view to outside, privacy, and thermal comfort [10]. 
Movable solar shading devices such as roller shades, curtains, and blinds can ensure a maximum energy saving while maintaining the best visual and thermal comfort and access to natural daylight. A number of research studies have reported the performance of movable solar shades. For example, Tzempelikos [11] assumed that roller shading devices were automatically closed when direct solar radiation is higher than $20 \mathrm{~W} / \mathrm{m}^{2}$, while Lee and Selkowitz [12] suggested a higher solar radiation of $94.5 \mathrm{~W} / \mathrm{m}^{2}$ for shades to be fully closed. Reinhart [13] assumed a similar control strategy where window blinds will be automatically closed as long as the direct solar radiance is above $50 \mathrm{~W} / \mathrm{m}^{2}$. These research studies all reported a significant improvement of building energy performance while maintaining a comfortable indoor thermal condition. Christopher et al. [14] compared the annual building energy consumption of five manual blind control algorithms. They found that the annual energy consumption differences ranged from $8.1 \%$ to $18.3 \%$ compared to buildings without manual shading devices. However, these studies not only crudely oversimplify occupants' control of solar shades, but also neglect the variability induced by the stochastic characteristics in occupant behavior [15].

To include the stochastic behavior in shade control, researchers such as Nicol [16] and Haldi [17,18] used logit regression to infer a probability distribution to describe occupants' shade action. However, there are some limitations in their models such as they merely considered two solar shading states (fully open and fully closed) and partly closed shades were not included, which was not in accordance with the real condition. Furthermore, occupants' stochastic behavior cannot be modeled in most building simulation programs (DOE-2 [19], EnergyPlus [20], TRNSYS [21], Esp-r [22], DeST [23,24]).To improve the accuracy of predicting occupants' solar shade control, the author developed a stochastic model for manual solar shades that considers partly shaded states and the performance of stochastic control can be quantitatively predicted by a coupling simulation [15]. The thermal, visual, and overall energy performances have been investigated in previous papers $[15,25,26]$. It was found that manual solar shades can improve indoor thermal comfort conditions by $154 \%$ compared to Low-E windows [25], and the Useful Daylight Index (UDI) can also be improved by about 30\% with less daylight illuminance fluctuation and more comfortable daylight distribution due to the manual control of solar shades. In addition, the Daylight Glare Index (DGI) and Daylight Glare Probability (DGP) were used to assess the glare risks of manual solar shades, which demonstrated a significant reduction (about 22\%) in intolerable glare compared to Low-E windows. Nevertheless, the results also found that occupants' action on solar shades was not always effective in minimizing glare risks, with about $12 \%$ of working hours experiencing intolerable glare [26]. A similar study on daylighting and the visual comfort performance of movable blinds has been conducted by Umberto Berardi and Taoning Wang [27], who recommended considering occupants' behavior to accurately evaluate the influence of the adjustment of shading devices on the building performance.

Thus, there is a need to further understand the stochastic characteristics of manual solar shades in order to improve the building performance of manual shades. Some research studies have conducted observations to analyze the characteristics of manual solar shades. Haldi et al. found that shade adjustment occurred mainly after arrival and/or before departure [17]. However, Rea reported contradicting findings. They found that the time of day had a negligible impact on shade actions [28]. Rubin et al. [29] reported that the seasonal effect on manual shade adjustment was not significant, while Zhang et al. found that window blinds varied seasonally for east, west, and south facades [30]. In addition, many studies reported that occupants adjust solar shades very infrequently (the shade movement rate is only about 1 /day) or even never [25,31,32]. However, these studies did not give a detailed and statistical analysis of the stochastic characteristics of manual solar shades. Furthermore, the effectiveness of manual shades, an important index when analyzing building energy performance, has also not been quantitatively evaluated. Therefore, this paper uses statistical indicators to systematically evaluate the randomness of manual shade control and introduces an index to calculate the effectiveness of manual shades. 


\section{Methodology}

\subsection{Stochastic Model}

This research is a continuation of previous research [15]. A Markov stochastic model for manual solar shades developed in the previous study was used in this paper [15]. This model was constructed based on field measurements and divided solar shades into five shading states (shade window area of $0 \%, 25 \%, 50 \%, 75 \%$, and $100 \%$, respectively). It is an improved model compared to other previous models [16,18], since it reflects occupants' real shade control behavior (windows were partly shaded). This model for solar shades was built in Building Controls Virtual Test Bed (BCVTB), a software environment developed by the Lawrence Berkeley National Laboratory [33], for co-simulation with EnergyPlus. A brief description of how this stochastic model is constructed and the co-simulation is conducted can be seen in Figure 1. More detailed information on this stochastic model and co-simulation can be found in a previous paper [15].

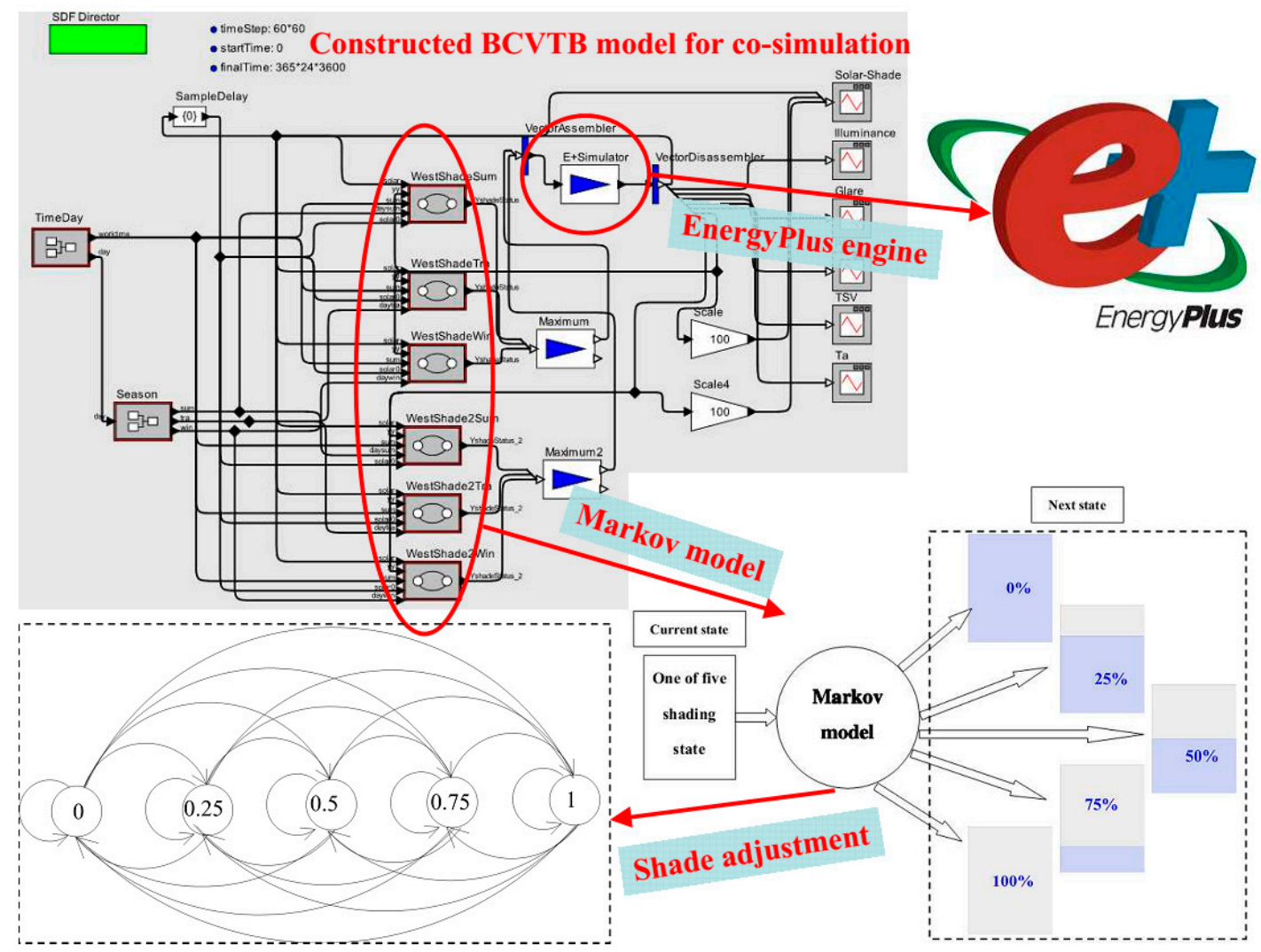

Figure 1. A graphic illustration of the developed method for the co-simulation of the performance of manual solar shades.

A typical office room in Ningbo (a typical city in a hot summer and cold winter zone of China) was selected. The details of the building, as well as other settings according to the design standard in this climate region, are listed in Table 1. This room was modeled in EnergyPlus and co-simulated in BCVTB. Manual solar shades were compared with automatically controlled ones which adopt a simple control strategy that assume occupants will bring sunlight into the interiors in winter and close shades in the summer to block excessive heat gains. A detailed description of this control strategy is given in Table 2. 
Table 1. The dimension and setting of the building enveloped and HVAC etc.

\begin{tabular}{|c|c|}
\hline Parameter & Value \\
\hline Orientation & West \\
\hline Dimension & Room: $4 \times 4 \times 3 \mathrm{~m}$, Window: $3.8 \times 2.8 \mathrm{~m}$ \\
\hline Building envelope & $\begin{array}{l}\text { U-value for external wall: } 1 \mathrm{~W} / \mathrm{m}^{2} \mathrm{~K} \text {, and adiabatic for internal walls, roof and floor; } \\
\text { Two window settings for comparison: (1) clear double-pane window (U-value: } \\
\left.3.6 \mathrm{~W} / \mathrm{m}^{2} \mathrm{~K}\right)+ \text { manually controlled solar shades (MShade); (2) clear double-pane } \\
\left.\text { window (U-value: } 3.6 \mathrm{~W} / \mathrm{m}^{2} \mathrm{~K}\right)+ \text { automatically controlled solar shades (AShade) }\end{array}$ \\
\hline Work time & 8:00-17:00 \\
\hline HVAC & Temperature: $20-26^{\circ} \mathrm{C}$, run time: 8:00-17:00 \\
\hline Interior heat generation & Light density: $11 \mathrm{~W} / \mathrm{m}^{2}$; equipment: $20 \mathrm{~W} / \mathrm{m}^{2}$ \\
\hline Fresh air & $40 \mathrm{~m}^{3} / \mathrm{h} \cdot \mathrm{p}$ \\
\hline
\end{tabular}

Table 2. Solar shading control strategy for automated solar shades.

\begin{tabular}{cccl}
\hline Season & Time & \multicolumn{1}{c}{ Shading Sate } & \multicolumn{1}{c}{ The Aim of the Control } \\
\hline \multirow{2}{*}{ Summer } & Daytime & Shade $2 / 3$ of window area & $\begin{array}{l}\text { Block excessive solar gain and keep enough } \\
\text { daylight }\end{array}$ \\
\cline { 2 - 4 } & Nighttime & Fully open & $\begin{array}{l}\text { Enable natural ventilation to decrease indoor } \\
\text { temperature }\end{array}$ \\
\hline \multirow{2}{*}{ Transition } & All time & Shade $1 / 2$ of window area & $\begin{array}{l}\text { Try to get a balance between solar radiation } \\
\text { and daylight }\end{array}$ \\
\hline \multirow{2}{*}{ Winter } & Daytime & Fully open & Admit solar heat to warm indoor space \\
\cline { 2 - 4 } & Nighttime & Fully closed & Reduce heat loss \\
\hline
\end{tabular}

\subsection{Statistic Analysis}

To analyze the stochastic characteristics of manual solar shades, the shading coefficient (Sc value, here it equals one minus the window shaded ratio. For example, if $25 \%$ of the window area is shaded, then Sc $=1-0.25=0.75$ ), a commonly used index when evaluating solar shading performance, was considered in this paper. Thus, a lower Sc value indicates a higher shading performance and consequently a lower cooling demand. According to the distribution of the hourly variation and seasonal difference of Sc values for manual solar shades, the stochastic characteristics of occupants' behavior on solar shades can be inferred. In addition, statistical indicators (parameter and non-parameter tests) were used to quantitatively evaluate the potential difference of shade behavior among different seasons.

In addition, a mathematical index (autocorrelation function) for identifying repeating patterns (e.g., the presence of a periodic signal that has been buried under noise) was used in this paper to check whether occupants' stochastic control on shades was repeatable. Informally, it is the similarity between observations as a function of the time separation between them. In statistics, the autocorrelation function (ACF) of a random process (here, it is occupants' stochastic control on solar shades) describes the correlation between the process at different points in time. The ACF for lag $\mathrm{k}$ can be calculated as follows:

$$
r_{k}=\frac{c_{k}}{c_{0}}
$$

where $c_{k}=\frac{1}{T-1} \sum_{t=1}^{T-k}\left(y_{t}-\bar{y}\right)\left(y_{t+k}-\bar{y}\right)$ is the autocovariance function and $c_{0}$ is the sample variance of the time series. $y$ is the sample value of the time series(here, it is the hourly Sc value), $\mathrm{k}$ is the time lag, and $\mathrm{T}$ is the length of the time series. The autocorrelation function $\left(r_{k}\right)$ is one of the tools used to find 
patterns in the data. Specifically, the autocorrelation function reveals the correlation between points separated by various time lags.

The strength of using statistical indicators to evaluate the randomness of manual shade control is that statistical analysis is a universal method with which to assess the validity of a conclusion. Parametric tests involve specific probability distributions (such as the normal distribution) and the tests involve an estimation of the key parameters of that distribution from the sample data. Non-parametric tests are also called distribution-free tests since they are based on fewer assumptions. Thus, there is less of a possibility to reach incorrect conclusions because assumptions about the population are unnecessary. However, nonparametric tests are generally less powerful than their parametric counterparts. For this study, the selection between a parametric and non-parametric test will be based on the test of sample distribution.

To evaluate the energy performance, an index used to calculate the effectiveness of manual solar shade control will be introduced. This index is based on the cooling and heating energy demand and is compared with automatically controlled shades as described in Table 2. It can be expressed as:

$$
E_{\mathrm{ff}}=\frac{E_{A}}{E_{M}} \times 100 \%
$$

where $E_{\mathrm{ff}}$ is the effectiveness of Mshade, $E_{A}$ is the energy demand for Ashade, and $E_{M}$ is the energy demand for Mshade. Due to the stochastic characteristics of occupant behavior, manual shades are not always kept at optimal (or near optimal) positions with minimum heating or cooling energy demands. Therefore, $E_{M}$ is usually higher than $E_{A}$. If manual shades are kept at the same near optimal positions as automatically controlled ones, $E_{M}$ will be very close to $E_{A}$ and $E_{\mathrm{ff}}$ will approach $100 \%$, indicating a high effective control by occupants. Using Equation (2), one can easily assess the effectiveness of occupants' control on solar shades.

\section{Results and Discussion}

\subsection{Sc Distribution}

The hourly Sc distribution during the whole year is shown in Figure 2. Since the shade adjustment only occurs at working hours (8:00-17:00), the Sc values for other hours are not illustrated in this figure. It can be seen that the $\mathrm{Sc}$ value changes from 0 (fully shaded) to 1 (fully open), indicating that occupants may deploy shades to all possible positions. Meanwhile, high and low Sc values were observed in winter, summer, and transition seasons. However, no significant difference between seasons can be visually inspected.

Figure 3 further gives the histogram of the hourly Sc value distribution. The shape of the distribution looks like a normal distribution, with most Sc values falling in the range of 0.3-0.7. Occupants only kept their shades at two extreme positions (fully shaded and fully open) for about $7 \%$ of the working hours. This means that for most of the time, the windows were partially shaded by shades.

On the other hand, the daily average (10 working hours) Sc values are given in Figure 4 . It can be seen that most $\mathrm{Sc}$ values fall in the range of $0.2-0.8$ and the fluctuation of daily values is also significant. In addition, no daily average Sc equals 0 or 1 , indicating that the fully open or fully closed position of shades will not be kept unchanged for a whole day (10 working hours). For seasonal comparison, no significant difference between seasons can be observed from this figure. The statistic analysis of seasonal difference will be further conducted in Section 3.3. 


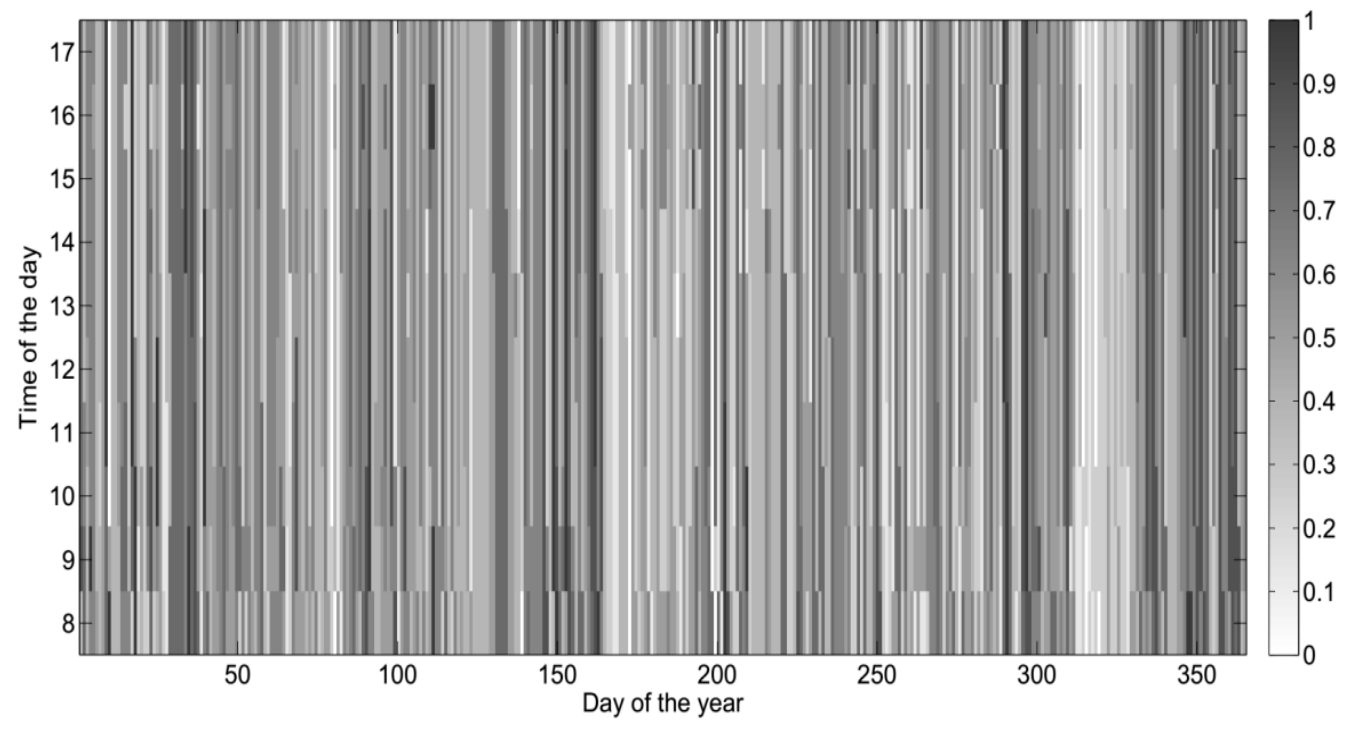

Figure 2. Hourly Sc distribution during the year.

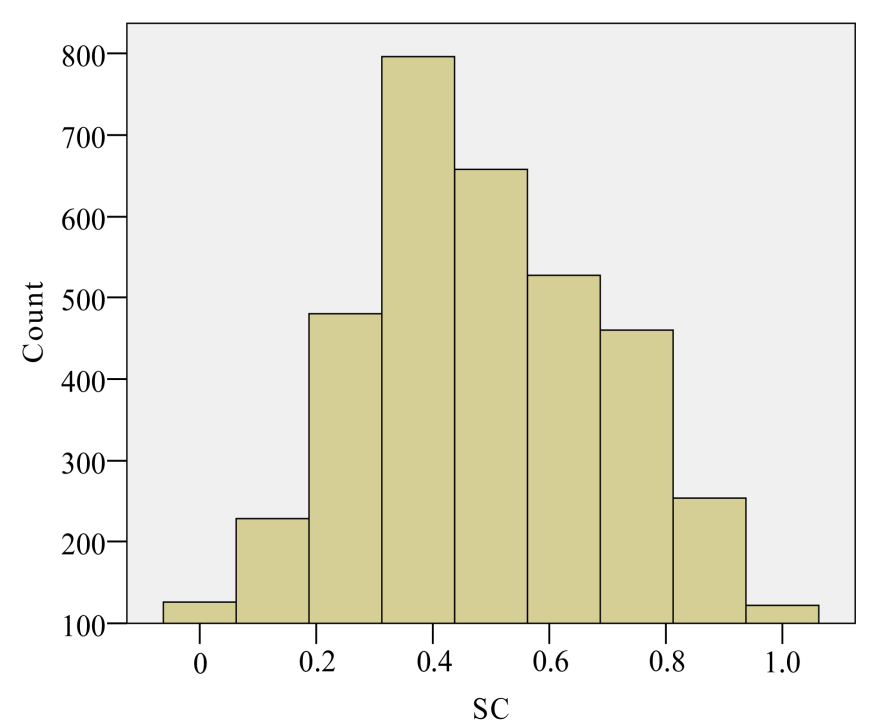

Figure 3. Histogram of the hourly Sc value distribution during the year.

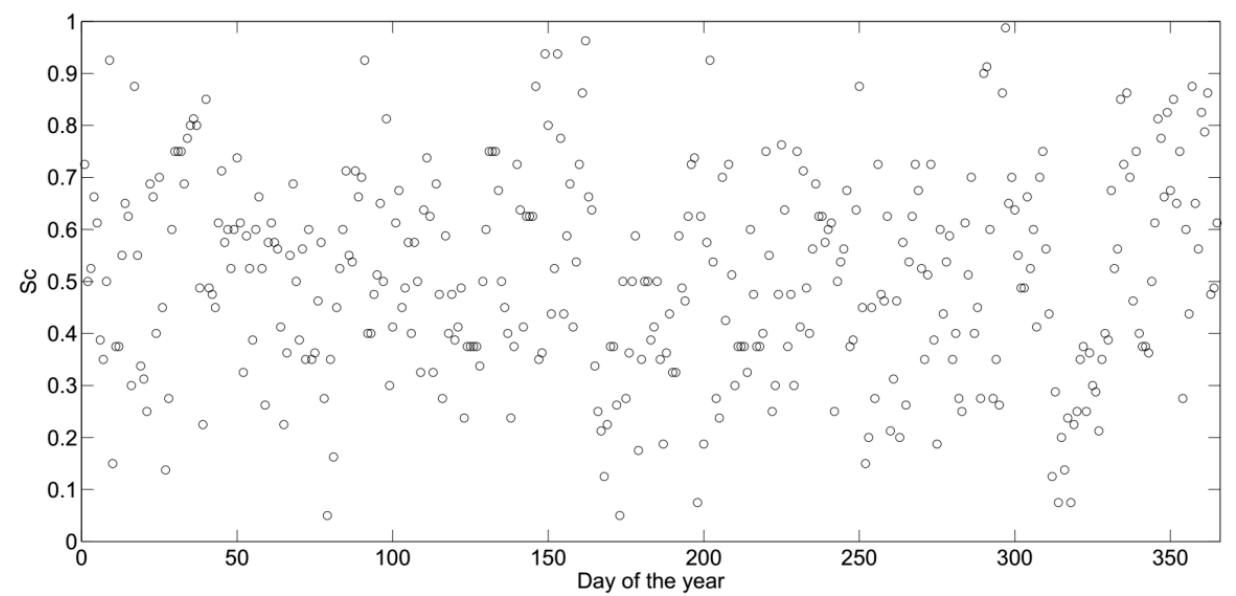

Figure 4. Daily average (10 working hours) Sc values. 


\subsection{Sc Change}

Occupants change the shade positions infrequently, with more than $3000 \mathrm{~h}$ ( $90 \%$ of working hours) experiencing no movement of shades (see Figure 5). For most days, the Sc value only changes once during a day, indicating a daily shade change rate of about 1. Figure 6 gives the hourly change of the Sc value during the year. For a few days, no change in the Sc value was observed (the change of Sc equals 0). The largest change of Sc was less than 0.8 and most values (except $4 \mathrm{~h}$ ) fall in the range of $0.1-0.5$. This means that occupants usually adjust the shade position gradually with a small fraction (less than $50 \%$ of the window area) and are less likely to change shades from fully open to fully closed and vice versa (the change of $\mathrm{Sc}$ is 1). However, previous research or design standards assumed that shades were fully open when solar radiation falling on windows was not intensive and would be changed to fully closed when solar radiation was higher than a certain level. Therefore, the previous assumptions were not reasonable and would lead to a deviation of the energy performance of manual solar shades. This finding is important since it will improve the assumption about the possible shade change (Sc value change) when predicting the performance of manual solar shades.

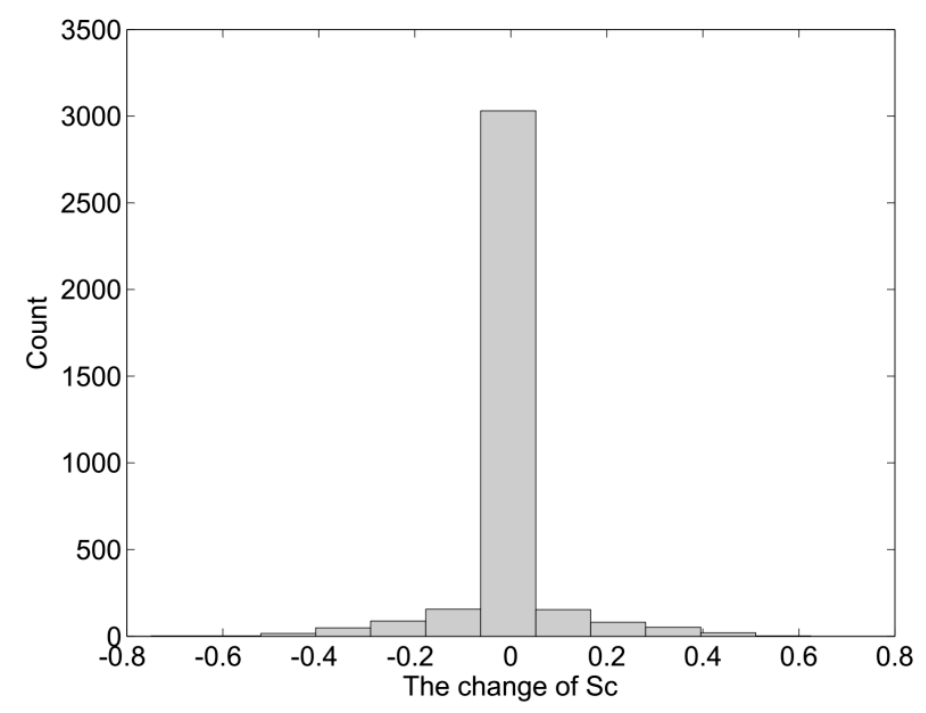

Figure 5. Histogram of the change of the Sc value during the year.

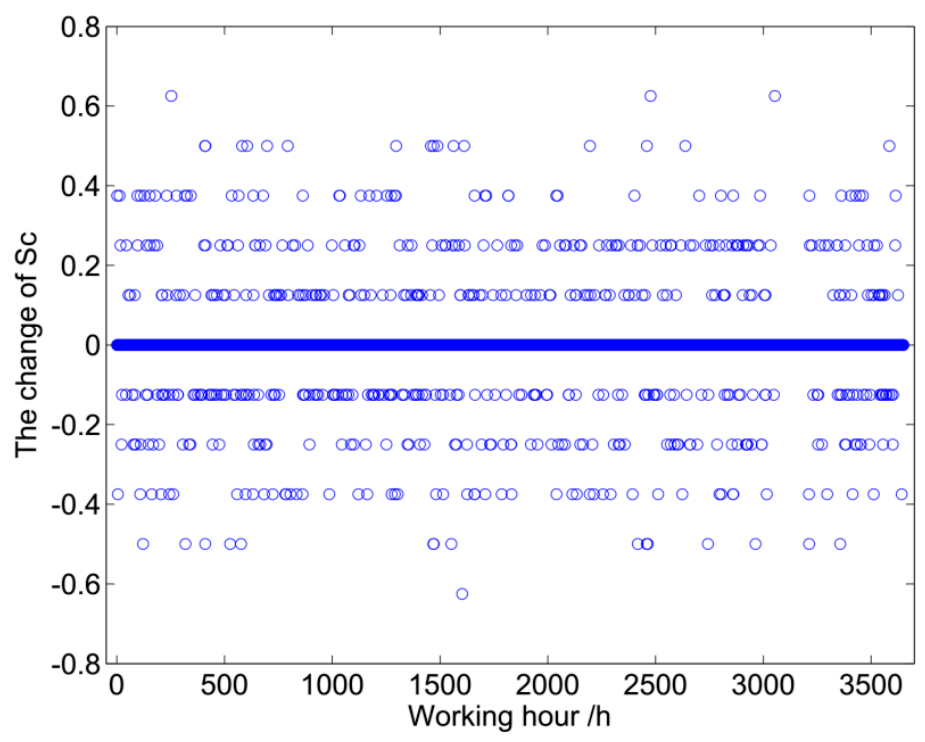

Figure 6. The hourly change of the Sc value during the year. 
When solar shades will be adjusted is another important factor in determining shade control behavior. Figure 7 presents the frequency of Sc change at each time point during the year. It can be seen that shade change is about one times more frequent during 9:00-13:00 than other time points. The highest frequency is about 80 , indicating that the shade change probability for this time point is about $22 \%(80 / 365)$ (or means that there will be a change of shade position at this time point during about 4.6 days $(365 / 80))$. The more frequent adjustment of solar shades in the morning than in the afternoon may be explained as follows: when solar radiation influences the west facade, occupants will adjust shades to block excessive radiation in order to avoid heat or glare problems and then keep shades at the same position for several hours, as long as the solar radiation is intensive.

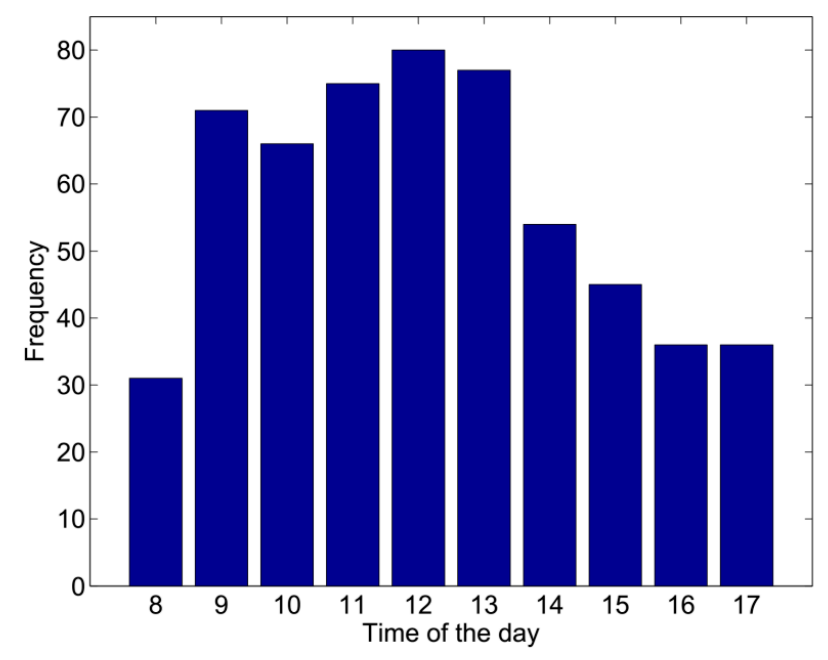

Figure 7. Frequency of Sc change at each time point during the year.

Figures 8 and 9 further illustrate the frequency of the Sc value increase and decrease at each time point during the year. The distribution shapes of these two figures at each time point are similar to that of Figure 7. Moreover, there is no significant difference between the Sc value increase and decrease. This reflects that occupants' shade control is stochastic and the probability of lowering or raising the shade position is very close for the whole year.

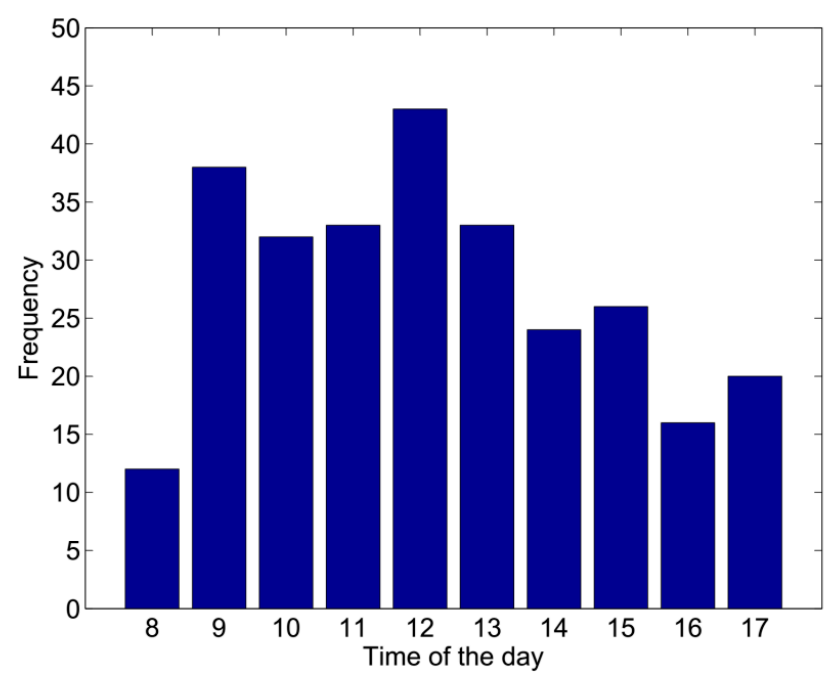

Figure 8. Frequency of Sc value increase at each time point during the year. 


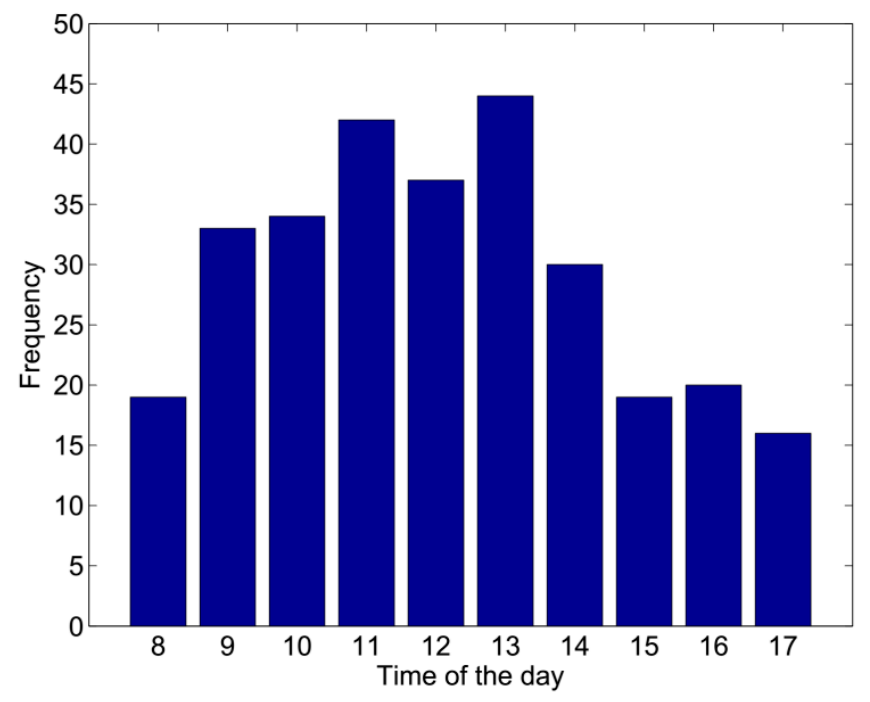

Figure 9. Frequency of Sc value decrease at each time point during the year.

\subsection{Seasonal difference}

In terms of the seasonal difference, three seasons were considered, with summer from days 152-273 (a total of 122 days), winter from days 1-58 and 334-365 (90 days), and the transition from days 59-151 and 274-333 (153 days). Thus, the number of hourly Sc values for the three seasons was different, with the transition season having (denoted as tra) $1530 \mathrm{~h}$, summer (denoted as sum) $1220 \mathrm{~h}$, and winter (denoted as win) $900 \mathrm{~h}$. Figure 10 gives the hourly Sc distribution for the three seasons. The overall distributions of the Sc value for the three seasons are similar, with tra having more hours at almost each Sc value.

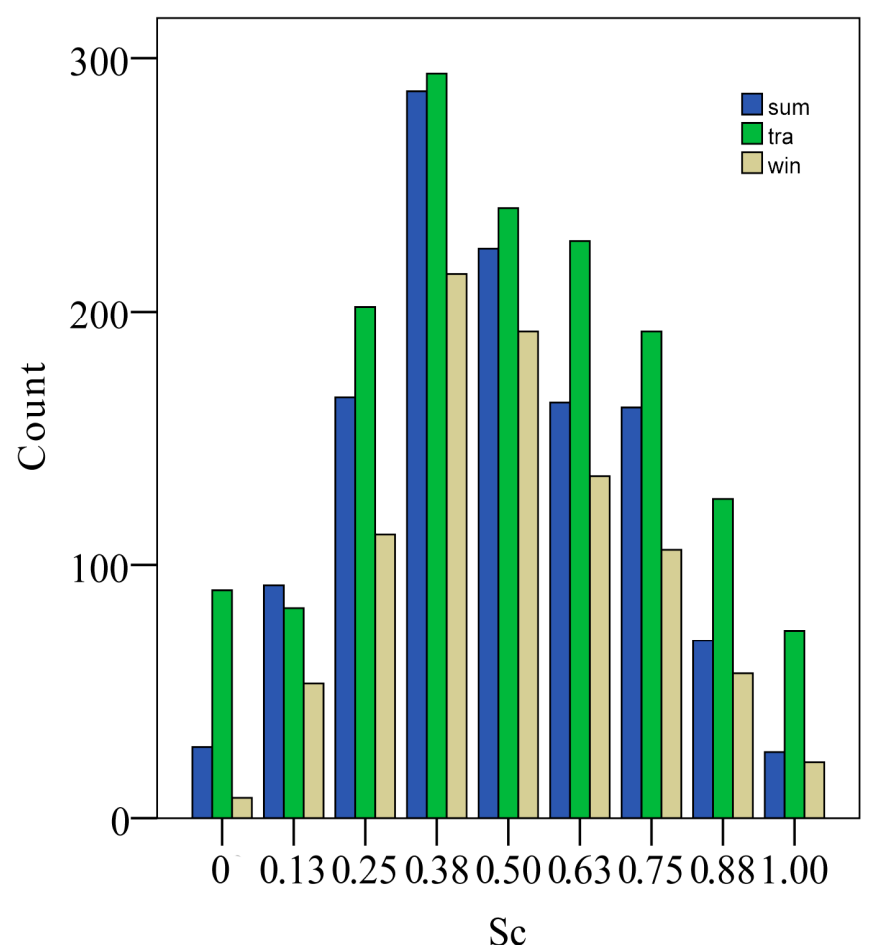

Figure 10. The hourly Sc distribution for the three seasons. 
To further analyze the distribution of the Sc value in different seasons, a box plot of the hourly Sc values in the three seasons is illustrated in Figure 11. It can be seen that the average Sc values for the three seasons are very close (about 0.5). Meanwhile, sum and win have almost the same distribution, while tra has more Sc values higher than 0.6 compared to the other two seasons.

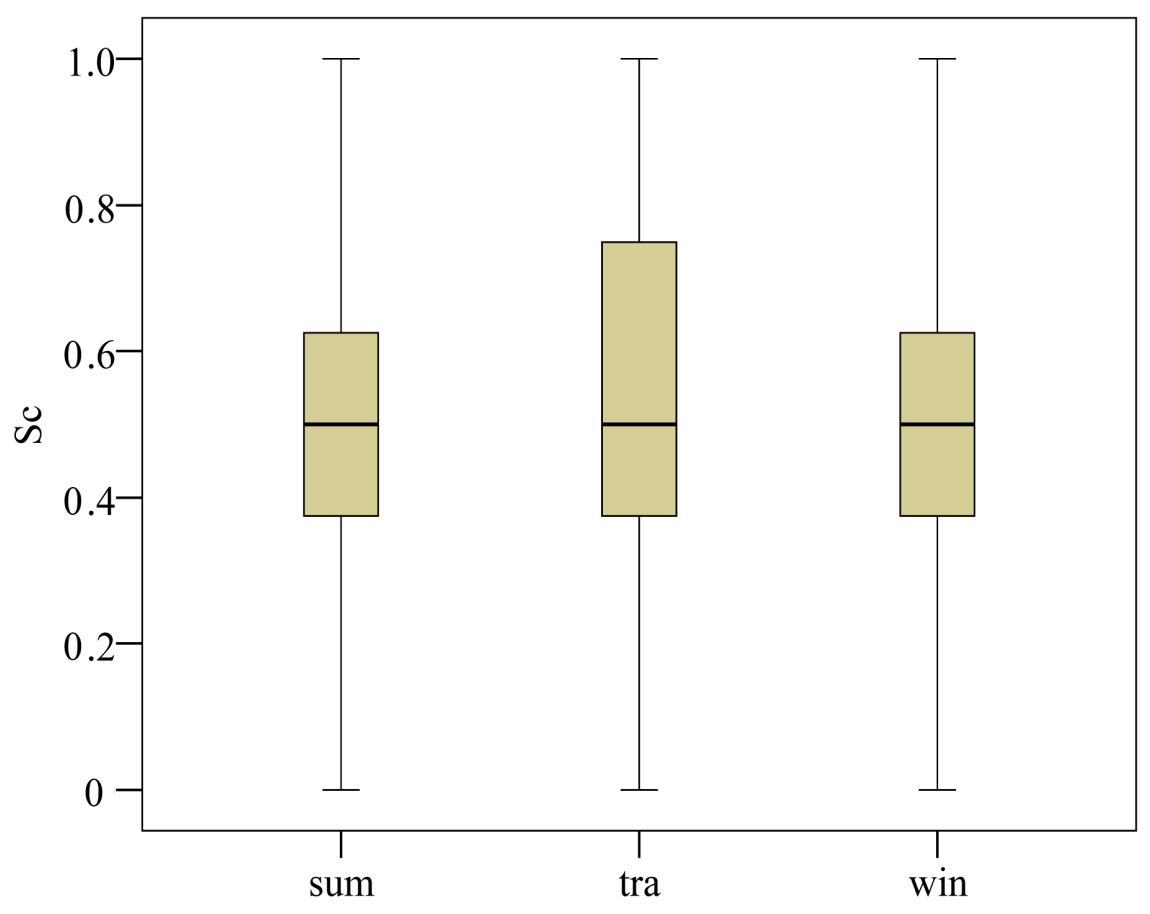

Figure 11. Box plot of hourly Sc values in three seasons.

To conduct the statistic analysis, the Kolmogorov-Smirnov test was used to check whether the Sc values in different seasons were of a normal distribution. The results showed that the asymptotic significance is $0.000(<0.05$, the significance level). This means that the null hypothesis should be rejected, indicating that the distribution of Sc does not resemble a normal distribution. Therefore, a parameter test (independent-samples $t$ test) is not applicable since this test assumes sampling from normal parent populations. Instead, an independent-samples Kruskal-Wallis test, a non-parametric method for testing whether samples originate from the same distribution, was used since it does not assume that the data are normal. The independent-samples Kruskal-Wallis test shows that the asymptotic significance is 0.078 ( $>0.05$, the significance level). It means that we should retain the null hypothesis, indicating that the distribution of the $\mathrm{Sc}$ value is the same across different seasons. Therefore, occupants' stochastic shade control behavior among different seasons is not statistically different, although there is little difference in the Sc distribution between seasons.

Figure 12 presents the ACF of hourly Sc values for different lag hours (here, 1-22 $\mathrm{h}$ were considered since they covered two days which were enough to check the daily periodic patterns of the Sc value). It can be seen from the figure that the ACF value decreases with increased lag hours. However, ACF drops to an almost constant value (no significant change when increasing lag hours) that falls out of their 95\% confidence intervals (95\%CI, U95: upper limit of 95\%CI, L95: lower limit of 95\%CI), which indicates that the series would not achieve a stationary condition. In other words, occupants' shade control behavior is not totally stochastic (such as a white noise) and shade adjustment at previous time steps influences current and future control. In addition, the trend of the fluctuation of Sc is not stable and changes with time. 


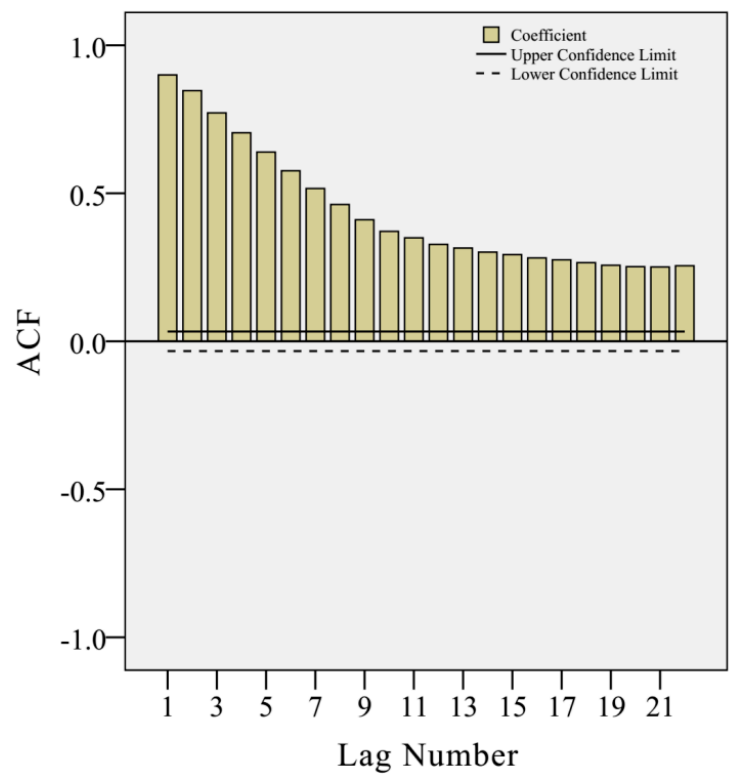

Figure 12. ACF of hourly Sc values.

\subsection{Energy Performance}

The cooling and heating energy performance of manual solar shades against automatically controlled ones is shown in Figures 13 and 14. It can be seen that Ashade performs better than Mshade for most of the time during the year, except for only a few hours. For the cooling demand, the big difference between Ashade and Mshade occurs in late afternoon in summer since this research focused on the west facade. The highest difference approaches $900 \mathrm{~W}$ at about 17:00, while at the beginning of the work day, the difference is only about 100-200 W. For the heating demand, Ashade performs better than Mshade in winter, while in the transition season, the situation is the opposite. This is because in the transition season, the window is assumed to be shaded by $50 \%$, as described in Table 2 . The largest heating difference is only about half of the largest cooling difference. Mshade has an annual cooling and heating increase of $536.3 \mathrm{kWh}$ and $88.8 \mathrm{kWh}$ compared to Ashade, respectively, corresponding to an increasing rate of $28.6 \%$ and $25.7 \%$. That means that the cooling and heating energy performance would be overestimated by more than $25 \%$ if manual solar shades are considered as ideally controlled.

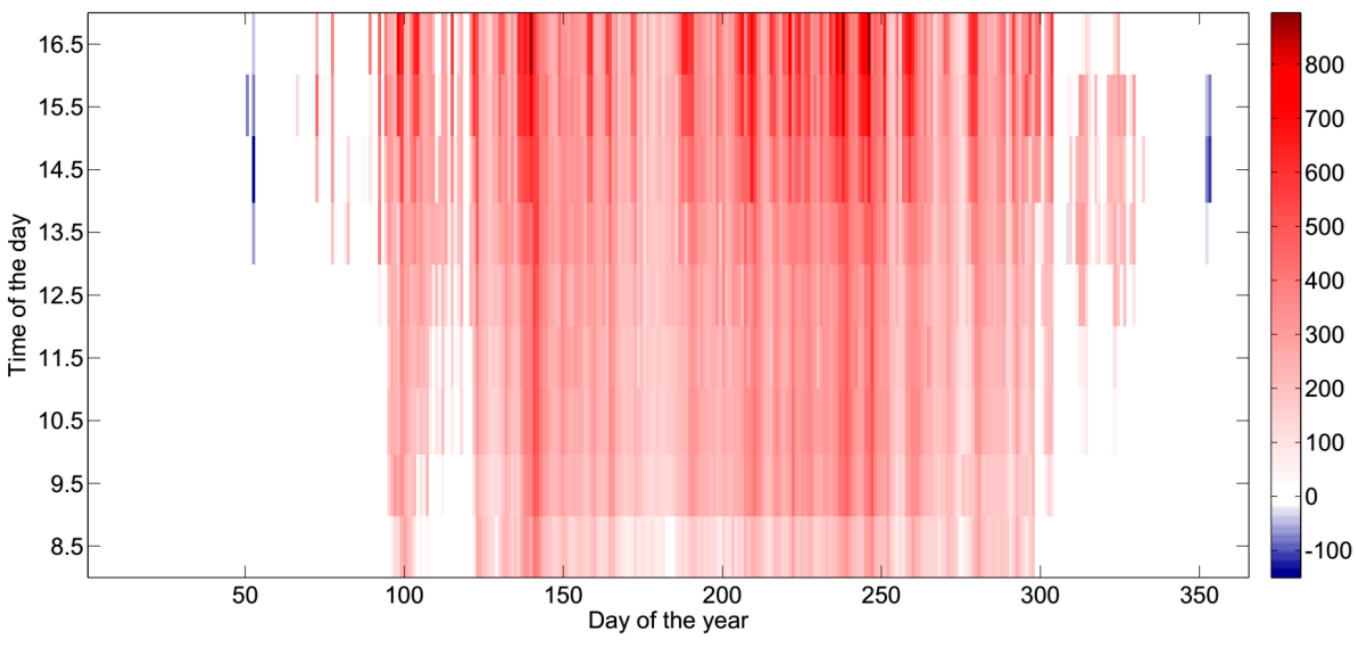

Figure 13. Cooling energy increase (W) of manual solar shades (Mshade) compared to automatically controlled ones (Ashade). 


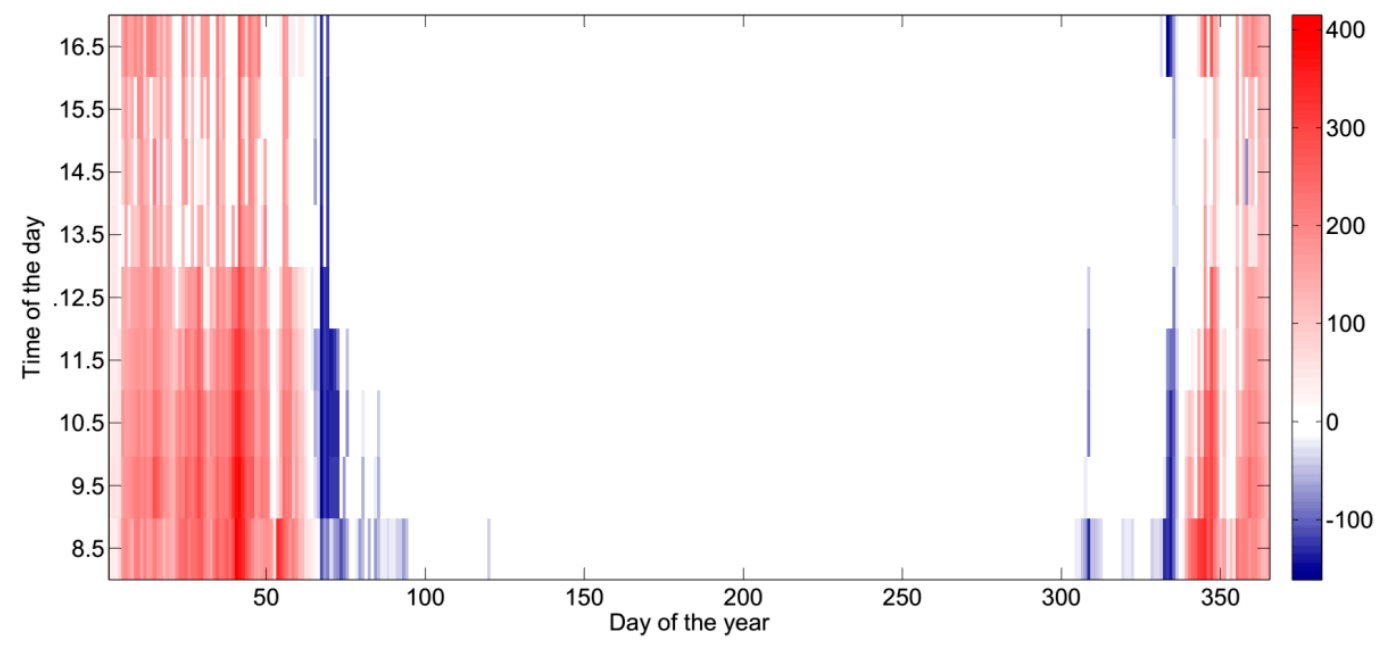

Figure 14. Heating energy increase (W) of manual solar shades (Mshade) compared to automatically controlled ones (Ashade).

To further investigate the overestimated energy performance, the ratios $\left(E_{\mathrm{ff}}\right)$ of the cooling and heating energy consumption of Ashade to Mshade are illustrated in Figures 15 and 16. It can be seen that during the hot summer period, this ratio reaches above 0.8 , while in the transition season, this ratio drops significantly from 0.8 to near 0 . This indicates that Mshade is more effective in summer than in the transition season. Due to the significant fluctuation of $E_{\mathrm{ff}}$ at each time point, the effectiveness of Mshade will be evaluated on a seasonal basis. According to these two figures, $E_{\mathrm{ff}}$ for cooling is $81.3 \%$ for summer and $46.4 \%$ for the transition season. $E_{\mathrm{ff}}$ for heating is much lower than cooling and it is only $51.9 \%$ for winter and $39.8 \%$ for the transition season. Therefore, there is a large potential for improving the effectiveness of Mshade in winter for the heating demand, as well as in the transition season for both heating and cooling.

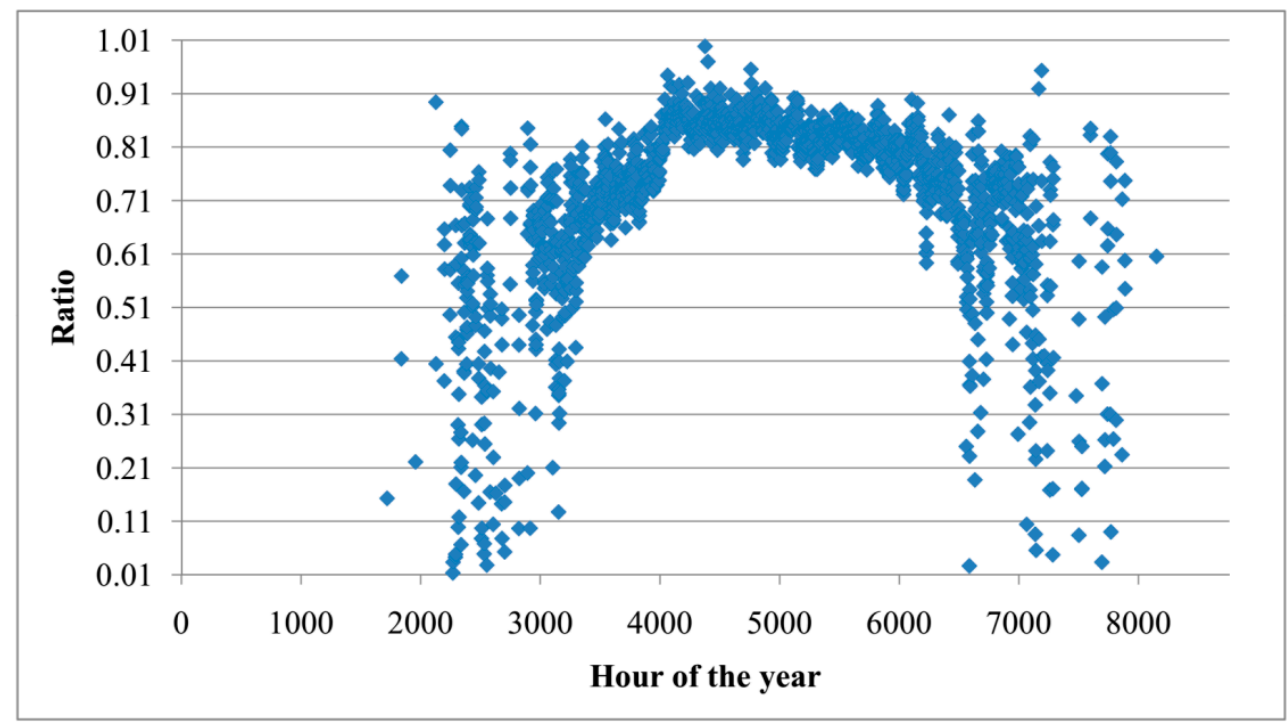

Figure 15. Ratio of cooling energy consumption of automatically controlled solar shades (Ashade) to manual shades (Mshade). 


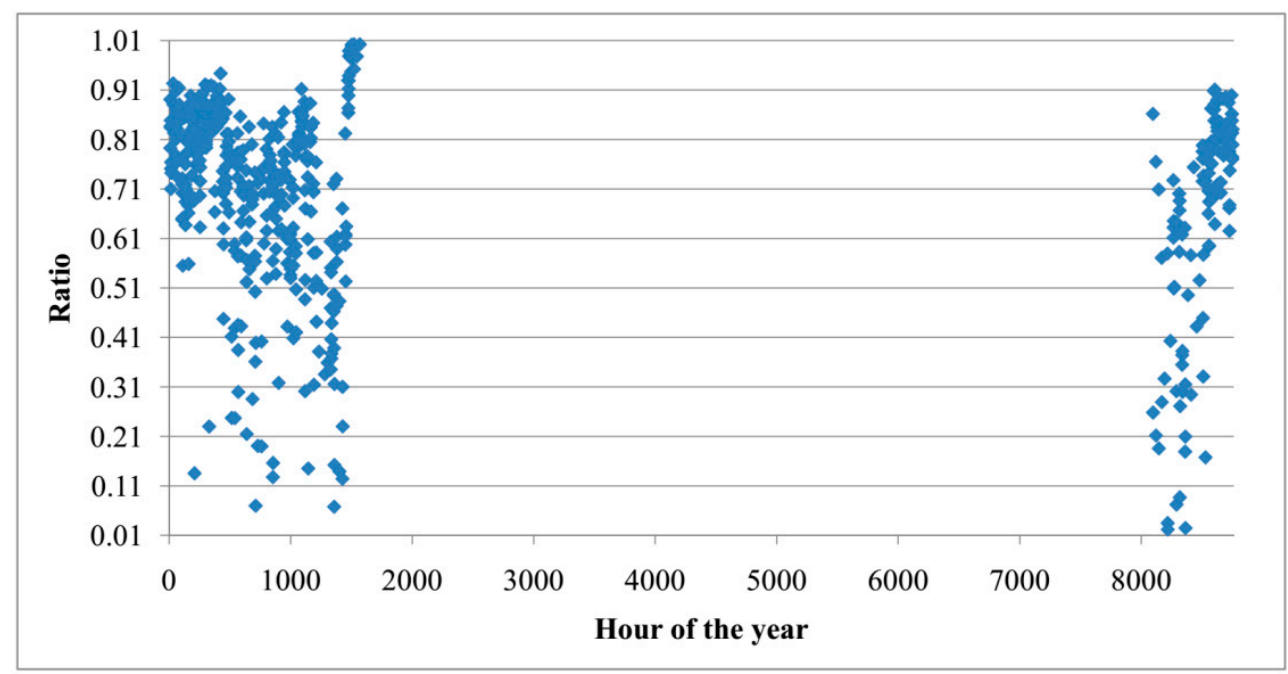

Figure 16. Ratio of heating energy consumption of automatically controlled solar shades (Ashade) to manual shades (Mshade).

\section{Conclusions}

This paper investigates the stochastic characteristics of manual solar shades and their influence on building energy performance. A stochastic model for manual solar shades developed by the author was used in this paper and a co-simulation-based occupant behavior analysis was conducted. An in-depth analysis on the shading performance of manual solar shades was performed by using non-parameter tests and the autocorrelation function in order to identify the potential occupant behavior patterns. The results show that occupants' stochastic shade control behavior among different seasons is not statistically different, although there is a little difference in the Sc distribution between seasons. In addition, the shade control behavior is not totally stochastic and shade adjustment at previous time steps influences current and future control. Meanwhile, the trend of the fluctuation of Sc changes with time. Furthermore, a new index was introduced to evaluate the effectiveness of manual solar shades in terms of energy performance. Using this index, the energy performance of manual solar shades was compared with automatically controlled ones. The result shows that the effectiveness of manual solar shades is between $39.8 \%$ and $81.3 \%$, and there is a large potential for improving the effectiveness of manual solar shades in winter for the heating demand, as well as in the transition season for both heating and cooling.

Further studies, including questionnaire surveys and field measurements, are needed to better understand shade control behavior in order to explain why there is no seasonal difference in shade adjustment and how previous shade control influences current actions. Meanwhile, occupants' adaptation to an indoor microclimate (thermal and visual comfort and air quality etc.) may also influence shade control behavior. Thus, an investigation of the interactions between occupants and acceptable comfort conditions will help understand the specific reasons for stochastic shade control and allow for identifying potential measures to improve the effectiveness of manual solar shades.

Acknowledgments: This work was supported by National Key Technology R\&D Program of the Ministry of Science and Technology under Grant 2013BAJ10B06 and Foundation of Ningbo University (XK115D230), and the authors would like to thank the K.C. Wong Magna Fund in Ningbo University.

Author Contributions: Jian Yao designed the study and wrote the manuscript. Rongyue Zheng helped revise the manuscript.

Conflicts of Interest: The authors declare no conflict of interest. 


\section{References}

1. Tzifa, V.; Papadakos, G.; Papadopoulou, A.G.; Marinakis, V.; Psarras, J. Uncertainty and method limitations in a short-time measurement of the effective thermal transmittance on a building envelope using an infrared camera. Int. J. Sustain. Energy 2017, 36, 28-46. [CrossRef]

2. Zheng, R.; Yao, J. The optimum energy saving measures for retrofitting residential buildings. Open House Int. 2016, 41, 88-92.

3. Marinakis, V.; Doukas, H.; Karakosta, C.; Psarras, J. An integrated system for buildings' energy-efficient automation: Application in the tertiary sector. Appl. Energy 2013, 101, 6-14. [CrossRef]

4. Echenagucia, T.M.; Capozzoli, A.; Cascone, Y.; Sassone, M. The early design stage of a building envelope: Multi-objective search through heating, cooling and lighting energy performance analysis. Appl. Energy 2015, 154, 577-591. [CrossRef]

5. Raeissi, S.; Taheri, M. Optimum overhang dimensions for energy saving. Build. Environ. 1998, 33, $293-302$. [CrossRef]

6. Valladares-Rendón, L.G.; Lo, S. Passive shading strategies to reduce outdoor insolation and indoor cooling loads by using overhang devices on a building. Build. Simul. 2014, 7, 671-681. [CrossRef]

7. Ebrahimpour, A.; Maerefat, M. Application of advanced glazing and overhangs in residential buildings. Energy Convers. Manag. 2011, 52, 212-219. [CrossRef]

8. Aldawoud, A. Conventional fixed shading devices in comparison to an electrochromic glazing system in hot, dry climate. Energy Build. 2013, 59, 104-110. [CrossRef]

9. Datta, G. Effect of fixed horizontal louver shading devices on thermal perfomance of building by TRNSYS simulation. Renew. Energy 2001, 23, 497-507. [CrossRef]

10. Bakker, L.G.; Hoes-van Oeffelen, E.C.M.; Loonen, R.C.G.M.; Hensen, J.L.M. User satisfaction and interaction with automated dynamic facades: A pilot study. Build. Environ. 2014, 78, 44-52. [CrossRef]

11. Tzempelikos, A.; Athienitis, A.K. The impact of shading design and control on building cooling and lighting demand. Solar Energy 2007, 81, 369-382. [CrossRef]

12. Lee, E.S.; Selkowitz, S.E. The Design and Evaluation of Integrated Envelope and Lighting Control Strategies for Commercial Buildings. Available online: https://www.osti.gov/scitech/biblio/10107748 (accessed on 19 June 2017).

13. Sun, L.; Lu, L.; Yang, H. Optimum design of shading-type building-integrated photovoltaic claddings with different surface azimuth angles. Appl. Energy 2012, 90, 233-240. [CrossRef]

14. Dyke, C.; Van Den Wymelenberg, K.; Djunaedy, E.; Steciak, J. Comparing Whole Building Energy Implications of Sidelighting Systems with Alternate Manual Blind Control Algorithms. Buildings 2015, 5, 467-496. [CrossRef]

15. Yao, J. Determining the energy performance of manually controlled solar shades: A stochastic model based co-simulation analysis. Appl. Energy 2014, 127, 64-80. [CrossRef]

16. Nicol, J.F. Characterising Occupant Behaviour in Buildings: Towards a Stochastic Model of Occupant Use of Windows, Lights, Blinds, Heaters and Fans. Available online: http://www.ibpsa.org/proceedings/BS2001/ BS01_1073_1078.pdf (accessed on 19 June 2017).

17. Haldi, F.; Robinson, D. On the behaviour and adaptation of office occupants. Build. Environ. 2008, 43, 2163-2177. [CrossRef]

18. Haldi, F.; Robinson, D. Adaptive actions on shading devices in response to local visual stimuli. J. Build. Perform. Simul. 2010, 3, 135-153. [CrossRef]

19. Birdsall, B.E.; Buhl, W.F.; Curtis, R.B.; Erdem, A.E.; Eto, J.H.; Hirsch, J.J.; Olson, K.H.; Winkelmann, F.C. The DOE-2 computer program for thermal simulation of buildings. AIP Conf. Proc. 1985, 135, 642-649. [CrossRef]

20. Crawley, D.B.; Lawrie, L.K.; Winkelmann, F.C.; Buhl, W.F.; Huang, Y.J.; Pedersen, C.O.; Strand, R.K.; Liesen, R.J.; Fisher, D.E.; Witte, M.J.; et al. EnergyPlus: creating a new-generation building energy simulation program. Energy Build. 2001, 33, 319-331. [CrossRef]

21. Beckman, W.A.; Broman, L.; Fiksel, A.; Klein, S.A.; Lindberg, E.; Schuler, M.; Thornton, J. TRNSYS The most complete solar energy system modeling and simulation software. Renew. Energy 1994, 5, 486-488. [CrossRef]

22. Strachan, P.A.; Kokogiannakis, G.; Macdonald, I.A. History and development of validation with the ESP-r simulation program. Build. Environ. 2008, 43, 601-609. [CrossRef] 
23. Yan, D.; Xia, J.; Tang, W.; Song, F.; Zhang, X.; Jiang, Y. DeST-An integrated building simulation toolkit Part I: Fundamentals. Build. Simul. 2008, 1, 95-110. [CrossRef]

24. Zhang, X.; Xia, J.; Jiang, Z.; Huang, J.; Qin, R.; Zhang, Y.; Liu, Y.; Jiang, Y. DeST-An integrated building simulation toolkit Part II: Applications. Build. Simul. 2008, 1, 193-209. [CrossRef]

25. Yao, J.; Chow, D.H.C.; Zheng, R.Y.; Yan, C.W. Occupants' impact on indoor thermal comfort: A co-simulation study on stochastic control of solar shades. J. Build. Perform. Simul. 2016, 9, 272-287. [CrossRef]

26. Yao, J.; Chow, D.; Chi, Y. Impact of Manually Controlled Solar Shades on Indoor Visual Comfort. Sustainability 2016, 8, 727. [CrossRef]

27. Berardi, U.; Wang, T. Daylighting in an atrium-type high performance house. Build. Environ. 2014, 76, 92-104. [CrossRef]

28. Rea, M.S. Window blind occlusion: a pilot study. Build. Environ. 1984, 19, 133-137. [CrossRef]

29. Rubin, A.I.; Collins, B.L.; Tibbott, R.L. Window Blinds as a Potential Energy Saver: A Case Study. Available online: https:/ / www.ncjrs.gov/pdffiles1/Digitization/64368NCJRS.pdf (accessed on 19 June 2017).

30. Zhang, Y.; Barrett, P. Factors influencing the occupants' window opening behaviour in a naturally ventilated office building. Build. Environ. 2012, 50, 125-134. [CrossRef]

31. Inoue, T.; Kawase, T.; Ibamoto, T.; Takakusa, S.; Matsuo, Y. The development of an optimal control system for window shading devices based on investigations in office buildings. ASHRAE Trans. 1988, 104, 1034-1049.

32. Inkarojrit, V. Balancing Comfort: Occupants' Control of Window Blinds in Private Offices. Available online: http:/ / escholarship.org/uc/item/3rd2f2bg\#page-1 (accessed on 19 June 2017).

33. BCVTB. Building Controls Virtual Test Bed. Available online: http://simulationresearch.lbl.gov/bcvtb (accessed on 19 June 2017).

(C) 2017 by the authors. Licensee MDPI, Basel, Switzerland. This article is an open access article distributed under the terms and conditions of the Creative Commons Attribution (CC BY) license (http://creativecommons.org/licenses/by/4.0/). 